Journal of Mathematics and Informatics

Vol. 15, 2019, 9-17

ISSN: 2349-0632 (P), 2349-0640 (online)

Published 20 January 2019

www.researchmathsci.org

DOI: http://dx.doi.org/10.22457/jmi.129av15a2

Journal of

Mathematics and

Informatics

\title{
Research on the Influence of Leadership Style on Error Management Climate
}

\author{
Jin-ming Zhang ${ }^{1}$, Chong-li Wang ${ }^{2}$ and Qing-hua $\mathrm{Li}^{3}$ \\ School of Economics and Management \\ Chongqing University of Posts and Telecommunications \\ Chongqing- 400065, Chongqing, China. \\ ${ }^{1}$ E-mail: 1509876953@qq.com \\ 2E-mail: 1763256864@qq.com; ${ }^{3}$ E-mail: 2235742767@qq.com \\ Received 6 December 2018; accepted 9 January 2019
}

\begin{abstract}
The mechanism of the influence of corporate leadership style on the error management climate is discussed. Based on the sample data of 616 middle and high-level managers, the relationship between paternal leadership and error management climate was tested. The results show that the positive error management climate can be formed through the direct role of benevolent leadership or moral leadership, and the negative error management climate can pass the direct role of authoritarian leadership or moral leadership. Based on this, management inspiration is proposed: According to different types of enterprises, leaders should adopt different parental leadership styles, formulate strict or loose enterprise systems, promote the formation of a suitable error management climate, and then improve corporate performance.
\end{abstract}

Keywords: Leadership style; Paternalistic leadership; Error management climate

AMS Mathematics Subject Classification (2010): 94B70

\section{Introduction}

The error management climate refers to organizational practices, procedures, and common attitudes related to errors. In short, it refers to the way in which organizations deal with errors [1]. Errors are everywhere [2], and in organizations, employees are inevitable because of the limitations of their personal knowledge, carelessness, and so on. Different leaders have different attitudes toward errors, and the error management climate presented by different organizations is also very different. Organizations with a positive error management climate [3] can play an active role in error, encouraging employees to analyze the causes of errors, communicate with each other and avoid the same errors. Organizations with a negative error management climate [3] will try to avoid employee errors and develop a series of strict reward and punishment systems and preventive measures.

In recent years, the climate of error management has been heatedly discussed by scholars at home and abroad. Among them, organizational learning, employee innovation behavior and team performance have become the focus of scholars' research [4]. However, most of these variables are consequence variables, and the academic community is still 


\section{Jin-ming Zhang, Chong-li Wang and Qing-hua Li}

unclear about the way in which the error management climate should be managed. In previous studies, leadership factors have long been regarded as a key factor affecting the formation and development of team climate [5], but also an important factor in the formation of error management climate [6]. After all, leadership is not only the setter of the error management system in the organization, but also the "wind vane" of the results when the employees make errors. The positive effect of the organization to emphasize the error or the negative effect depends on different leadership styles [7]. The positive/negative effects of transformational leadership and transactional leadership on the climate of error management have also been indirectly confirmed [8]. Unfortunately, researchers pay little attention to the direct influence of the two, and the way of influencing their influence is also not deep enough.

Based on this, this paper constructs a model of parental leadership and error management climate, tries to explore the factors affecting the climate of error management, studies the influence of paternal leaders on the special climate of the organization, and adds a new theoretical explanation for the role of paternal leadership.

\section{Research review}

\subsection{Patriarchal leadership}

Zheng Boxun et al. [9] divided paternalistic leadership into three dimensions: benevolent authoritarian and moral. The benevolent leadership demonstrates individual, family and family well-being to show personal, comprehensive and lasting care. Authoritarian leaders advocate power, control employees, and require employees to obey orders unconditionally. Moral leadership gain respect and recognition from their employees by demonstrating outstanding personal qualities. At the same time, these three leadership styles are not necessarily inseparable and can be explored separately.

\subsection{Error management climate}

The error management climate is a series of attitudes and methods adopted by the organization to deal with error management [1], which is divided into two dimensions: positive (open, learning-oriented) and negative (aversion, blame-oriented). The positive error management climate is similar to the error management culture of van Dyck et al. [2] and the open-oriented error management climate of Gold et al. [10]. This climate is more tolerant, allowing members of the organization to make errors and limit penalties for wrong behavior, emphasizing correcting errors, thoroughly analyzing wrong behaviors and underlying causes, supporting members of the organization to communicate with each other in order to provide solutions, and tending to a loose organizational culture [11]. Negative error management climate is similar to the error-averse culture of van Dyck et al .[2], and the blame-oriented error management climate of Gold et al. [10]. This kind of climate is more stringent, and members of the organization are not allowed to make errors. Members of the organization will try their best to hide errors because they are afraid of punishment, and they tend to organize culture seriously. According to the previous research of this group, this paper believes that the positive error management climate includes four dimensions: contingency processing, analytical solution, tolerance and sympathy, and negative error management climate including blaming a dimension [3]. In addition, since van Dyc et al. [2], regard the positive and negative error management climate as two different organizational climates, this paper will also discuss them 
Research on the Influence of Leadership Style on Error Management Climate separately.

\section{Theoretical basis and research hypothesis}

The benevolent leadership regards employees as family members and pays attention to the dual care of employees' work and life. When employees make errors, they maintain the face of the employees, try to understand the employees and seek reasons. According to the theory of social exchange, employees will be rewarded with the rewards of leadership, and then more actively demonstrate the work behavior of the leaders' expectations. The specific performance is more hard work, no longer afraid of errors in the work, and actively communicate, Mutual discussion to avoid the same error again, thereby forming a positive error management climate.

Authoritarian leaders usually have strict control over their employees, do everything in an arbitrary manner, and cannot tolerate errors. Because they can't tolerate errors in their work, and their behavior will give employees a depressed and inhumanized working climate, it will make the organization tend to reject errors in the practice of handling errors, and make some stricter procedures. The strict reward and punishment system, employees will also form a common attitude of rejection and avoiding errors. Thereby, a negative error management climate is formed.

Moral leaders are broad-minded, and they care and help employees at work. When an employee makes a error, the German leadership will take the initiative to understand the internal reasons, help the staff to relieve stress, and provide pertinent advice to make employees feel safe. The error tolerance of the leaders of the Bank of China has affected employees' attitudes toward errors and triggered the active imitation of employees. Employees are willing to communicate and communicate their errors with others, learn from them, improve their ability to work and avoid others making similar errors. As a result, a positive error management climate is formed.

Moral leaders are strict with themselves, lead by example in their work, dare to take responsibility, do their due diligence for the development of the organization, and strive to achieve the target performance. According to the follow-up theory, its noble personal ethics and good moral cultivation are examples for employees, which will induce employees to follow behaviors. The specific performance is to strictly demand themselves in the work, work harder for the interests of the organization, and fail to achieve the set goals. I feel ashamed, try my best to avoid error, and even ask for more serious punishment to avoid error again. Thereby, a negative error management climate is formed.

Therefore, the hypothesis is proposed:

H1: The benevolent leadership has a positive impact on the positive error management climate.

H2: The authoritarian leadership has a positive impact on the negative error management climate.

H3: The moral leadership has a positive impact on the positive error management climate.

H4: The moral leadership has a positive impact on the negative error management climate. 
Jin-ming Zhang, Chong-li Wang and Qing-hua Li

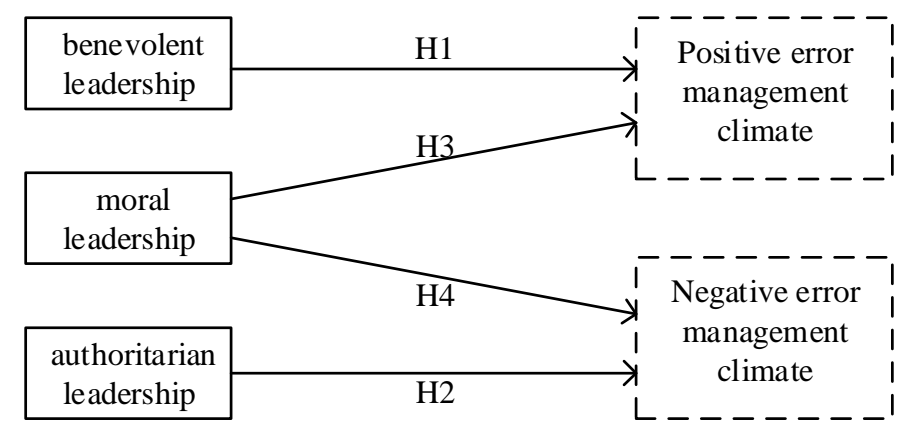

Figure 1: Research framework and conceptual model

\section{Research design}

\subsection{Experimental design and subjects}

We collaborate (pay) on a professional online survey company for sampling. According to our request, the company samples from its sample library according to certain rules. For this study, the benefit of online surveys is to reduce the impact of "social approval bias". The survey company distributed the questionnaire by email and station letter. First, the company screens eligible respondents from the sample library. The survey responded to the middle and high-level managers who were more aware of the company's error management. Subsequently, the survey company randomly selected 5,640 people from the sample pool of 310,000 middle and high-level managers to issue questionnaires to them. The scale of the questionnaire was estimated by the company based on the recovery rate of previous surveys. A total of 895 questionnaires were collected in this survey, the recovery rate was $15.87 \%$, and 616 valid questionnaires were obtained, with an effective rate of $68.83 \%$. Among the samples, males accounted for $56.82 \%$; among the academic distribution, $8.6 \%$ were junior colleges and below, $77.76 \%$ were undergraduate, $13.64 \%$ were masters and above, $29.54 \%$ were in 5 years, and $49.03 \%$ were in $5-10$ years. More than 10 years accounted for $21.43 \%$.

\subsection{Variable measurement}

The paternalistic leadership scale refers to the research of Zheng Boxun et al. [3], including benevolent leadership (5 items), authoritarian leadership (5 items), and moral leadership (5 items). The measurement of the error management climate is based on the scale developed by the research group. Including blame punishment (5 items), contingency processing ( 3 items), analytical solution (4 items), tolerance and sympathy ( 2 items) and prevention of recidivism (3 items).

The above variables were measured using the Likert 5 subscale: 1 is very inconsistent and 5 is very consistent. The research team discussed the first draft of the questionnaire with two management professors and two business managers. The revised questionnaire was used as the official version of the questionnaire. The paternalistic leadership scale and organizational culture scale used in this paper have been widely used and verified by the predecessors. The scale of the error management climate was developed by the research group through the standardized research procedure. Therefore, the content validity of the test questionnaire is acceptable.

\subsection{Analysis and discussion}


Research on the Influence of Leadership Style on Error Management Climate

\subsubsection{Reliability and validity}

The Cronbach's $\alpha$ coefficients of eight variables (benevolent leadership, authoritarian leadership, moral leadership, blame punishment, contingency treatment, analytical resolution, tolerance sympathy, and prevention of recidivism) all exceeded 0.6, indicating good internal consistency reliability. The eight-factor model fits well. The normalized factor load of each item was between 0.433 and 0.795 , and both reached a high level of significance $(\mathrm{p}<0.001)$, indicating good convergence efficiency. The correlation coefficient of each factor plus or minus twice the standard error (ie, the $95 \%$ confidence interval of the correlation coefficient) does not contain 1 or -1 , indicating a good discriminant validity. In addition, the fitting effect of the Harman single-factor model is significantly different from that of the eight-factor model, indicating that one latent variable cannot be used to explain all factors. Therefore, the homology error of the data is not serious.

Table 1: Correlation coefficient table

\begin{tabular}{|c|c|c|c|c|c|c|}
\hline & & $\begin{array}{l}\text { Benevolent } \\
\text { Leadership }\end{array}$ & $\begin{array}{c}\text { Authoritarian } \\
\text { Leadership }\end{array}$ & $\begin{array}{c}\text { Moral } \\
\text { Leadership }\end{array}$ & $\begin{array}{c}\text { Positive } \\
\text { EMC }\end{array}$ & $\begin{array}{c}\text { Negative } \\
\text { EMC }\end{array}$ \\
\hline \multirow[t]{2}{*}{$\begin{array}{l}\text { Benevolent } \\
\text { Leadership }\end{array}$} & $\begin{array}{l}\text { Pearson } \\
\text { Correlation }\end{array}$ & 1 & -.008 & $.637^{* *}$ & $.433^{* *}$ & $.228^{* *}$ \\
\hline & $\begin{array}{l}\text { Sig. (2- } \\
\text { tailed) }\end{array}$ & & .847 & .000 & .000 & .000 \\
\hline \multirow[t]{2}{*}{$\begin{array}{l}\text { Authoritarian } \\
\text { Leadership }\end{array}$} & $\begin{array}{l}\text { Pearson } \\
\text { Correlation }\end{array}$ & -.008 & 1 & $-.183^{* *}$ & $-.125^{* *}$ & $.383^{* *}$ \\
\hline & $\begin{array}{l}\text { Sig. (2- } \\
\text { tailed) }\end{array}$ & .847 & & .000 & .002 & .000 \\
\hline \multirow[t]{2}{*}{$\begin{array}{l}\text { Moral } \\
\text { Leadership }\end{array}$} & $\begin{array}{l}\text { Pearson } \\
\text { Correlation }\end{array}$ & $.637^{* *}$ & $-.183^{* *}$ & 1 & $.447^{* *}$ & .078 \\
\hline & $\begin{array}{l}\text { Sig. (2- } \\
\text { tailed) }\end{array}$ & .000 & .000 & & .000 & .052 \\
\hline \multirow[t]{2}{*}{ Positive EMC } & $\begin{array}{l}\text { Pearson } \\
\text { Correlation }\end{array}$ & $.433^{* *}$ & $-.125^{* *}$ & $.447^{* *}$ & 1 & $.159^{* *}$ \\
\hline & $\begin{array}{l}\text { Sig. }(2- \\
\text { tailed) }\end{array}$ & .000 & .002 & .000 & & .000 \\
\hline \multirow[t]{2}{*}{$\begin{array}{l}\text { Negative } \\
\text { EMC }\end{array}$} & $\begin{array}{l}\text { Pearson } \\
\text { Correlation }\end{array}$ & $.228^{* *}$ & $.383^{* *}$ & .078 & $.159^{* *}$ & 1 \\
\hline & $\begin{array}{l}\text { Sig. (2- } \\
\text { tailed) }\end{array}$ & .000 & .000 & .052 & .000 & \\
\hline
\end{tabular}

Note: $1 . \mathrm{N}=616 ; 2$. Positive EMC $=$ Positive error management climate, Negative $\mathrm{EMC}=$ Negative error management climate $3 .{ }^{* *}$. Correlation is significant at the 0.01 level (2-tailed). 
Jin-ming Zhang, Chong-li Wang and Qing-hua Li

\subsubsection{Hypothesis test}

We use the structural equation model to test the relevant hypotheses. The direct effect model fits well (see Table 2).

Table 2: Fitting indicators of direct effects

\begin{tabular}{ccccccc}
\hline$\chi^{2}$ & $\mathrm{df}$ & $\chi^{2} / \mathrm{df}$ & RMSEA & NNFI & CFI & IFI \\
3112.836 & 889 & 3.502 & 0.064 & 0.922 & 0.927 & 0.927 \\
\hline
\end{tabular}

Table 3: Path factors and t values of leadership style and error management climate

\begin{tabular}{|c|c|c|c|c|c|}
\hline \multicolumn{2}{|c|}{ Path } & \multirow[b]{2}{*}{$\begin{array}{c}\text { Path } \\
\text { coefficient }\end{array}$} & \multirow[b]{2}{*}{$\mathrm{t}$ value } & \multirow{2}{*}{$\begin{array}{c}\text { Correspo } \\
\text { nding } \\
\text { assumptio } \\
n\end{array}$} & \multirow[b]{2}{*}{ test result } \\
\hline starting point & end & & & & \\
\hline \multirow{4}{*}{$\begin{array}{l}\text { benevolent } \\
\text { leadership }\end{array}$} & $\begin{array}{c}\text { Contingency } \\
\text { processing }\end{array}$ & $0.456^{* * *}$ & 4.623 & \multirow{4}{*}{ H1 } & \multirow{4}{*}{$\begin{array}{l}\text { Partial } \\
\text { support }\end{array}$} \\
\hline & $\begin{array}{c}\text { Analytical } \\
\text { solution }\end{array}$ & $-0.216^{*}$ & -2.405 & & \\
\hline & $\begin{array}{l}\text { tolerance } \\
\text { sympathy }\end{array}$ & $0.498^{* * *}$ & 5.549 & & \\
\hline & $\begin{array}{c}\text { prevention of } \\
\text { recidivism }\end{array}$ & 0.012 & 0.148 & & \\
\hline $\begin{array}{c}\text { authoritarian } \\
\text { leadership }\end{array}$ & $\begin{array}{c}\text { blame } \\
\text { punishment }\end{array}$ & $0.586^{* * *}$ & 7.977 & $\mathrm{H} 2$ & support \\
\hline \multirow{5}{*}{$\begin{array}{c}\text { moral } \\
\text { leadership }\end{array}$} & $\begin{array}{c}\text { blame } \\
\text { punishment }\end{array}$ & $0.264^{* * *}$ & 4.932 & $\mathrm{H} 4$ & support \\
\hline & $\begin{array}{c}\text { Contingency } \\
\text { processing }\end{array}$ & 0.092 & 1.004 & \multirow{4}{*}{ H3 } & \multirow{4}{*}{$\begin{array}{l}\text { Partial } \\
\text { support }\end{array}$} \\
\hline & $\begin{array}{c}\text { Analytical } \\
\text { solution }\end{array}$ & $0.581^{* * *}$ & 6.029 & & \\
\hline & $\begin{array}{l}\text { tolerance } \\
\text { sympathy }\end{array}$ & 0.009 & 0.104 & & \\
\hline & $\begin{array}{l}\text { prevention of } \\
\text { recidivism }\end{array}$ & $0.510^{* * *}$ & 5.988 & & \\
\hline
\end{tabular}

According to Table 3, first, the benevolent leadership has a positive impact on contingency processing and tolerance and sympathy, consistent with theoretical expectations. The benevolent leadership has a negative impact on analysis and resolution, and it is not significant for preventing recidivism. This may be because the benevolent leadership shows the characteristics of caring for employees. Even when employees make errors, they will not be severely punished. Therefore, employees may have a mentality of "getting too much" and will not take the initiative to analyze the causes of errors. Solving the problem can not effectively prevent similar errors from occurring again, assuming H1 is partially supported. 
Research on the Influence of Leadership Style on Error Management Climate

Second, authoritarian leadership has a positive impact on the negative error management climate, assuming $\mathrm{H} 2$ is supported.

Third, the leadership of the German side has a positive impact on the analysis and prevention of recidivism, consistent with theoretical expectations. The leaders of the German side have a negative impact on tolerance and compassion. This may be because the leaders of the German bank infect the employees with high morality and cultivation, and the employees recognize and emulate the behavior of the leaders of the virtues. Therefore, when employees make errors, they will be ashamed and blame themselves. I feel that I should be tolerated, and other employees of the organization will try to avoid errors. The leadership of the German line is not significant in the contingency treatment. This may be because the contingency treatment cannot be improved by merely emulating the behavior of the leaders of the virtues. It should also combine the personal qualities of the employees (such as the understanding of the leaders of the virtues and the ability to handle things), and our The study did not control these aspects of the employee and thus showed insignificant characteristics, assuming that $\mathrm{H} 3$ was partially supported.

Fourth, the leadership of the German bank has a positive impact on the negative error management climate, assuming $\mathrm{H} 4$ is supported.

\section{Conclusion and discussion}

\subsection{Conclusion}

In this study, we discussed the relationship between leadership style and error management climate, and constructed a direct effect model that included paternalistic leadership and error management climate. An empirical study based on 616 middle- and high-level manager surveys found that the positive error management climate can be formed through the direct role of benevolent leadership or moral leadership; the negative error management climate can be formed through the direct role of authoritarian leadership or moral leadership.

\subsection{The theoretical and practical significance}

The theoretical significance of this paper includes the following two aspects: (1) The relationship between paternalistic leadership and error management climate is studied, and the theoretical framework of leadership style influence error management climate is constructed and supported by empirical data. As mentioned above, the influence factors of the error management climate have always lacked theoretical reasoning and empirical test. This paper perfects the related research in this field. The theoretical model constructed is a detailed description of the antecedent variables of the enterprise error management climate, which provides a reference for the research and theoretical perspective of the "black box" of opening the error management climate. (2) Exploring the mechanism of the role of paternalistic leadership in organizing a special climate. Previous studies on the influence of leadership style on organizational climate have mostly been conducted in Western contexts. Studies have shown that paternalistic leadership differs greatly from Western leadership styles (transactional leadership, transformational leadership, etc.). The three dimensions of paternalistic leadership have different dimensions and ways of affecting organizational climate. This paper supplements relevant research in this field and provides new theoretical explanations.

This research has certain implications for the management practice of enterprises. 
Jin-ming Zhang, Chong-li Wang and Qing-hua Li

On the one hand, if the type of enterprise is a company with low fault tolerance (such as medical industry, manufacturing, etc.), in order to improve corporate performance and promote organizational growth and development, business leaders can adopt the leadership styles of moral leadership and authoritarian leadership to create The organization needs a negative error management climate. On the other hand, if the type of business is a company with a high fault tolerance (such as the commodity industry), the company needs to create a positive error management climate. Leaders can adopt the two styles of virtue leadership and benevolent leadership to promote the formation of a positive error management climate.

\subsection{Research limitations}

The research limitations and expansion directions of this paper include: (1) The crosssection data is used in this paper, but the formation of the climate is long-term, and longitudinal research can be taken in the future. In addition, case studies can also be used to find some more subtle conclusions and deeper relationships between the two. (2) The theoretical framework of this paper is still not perfect. There may be other mediator variables and adjustment variables in the formation of error management climate. The cross-effects and adjustment effects between parental leaders' sub-dimensions also need further research.

\section{REFERENCES}

1. N.Keith and M.Frese, Enhancing firm performance and innovativeness through error management culture, Handbook of Organizational Culture and Climate, 9 (2011) 137-157.

2. D.C.Van, M.Frese, M.Baer, et al. Organizational error management culture and its impact on performance: A two-study replication, Journal of Applied Psychology, 90(6) (2005) 1228-1240.

3. Y.Li and L.Ma, Study on the influence mechanism of error management climate on knowledge conversion process, Information Studies Theory \& Practice, 37(2) (2014) 57-60.

4. P.C.Du, M.Li, and C.C.Wang, Study on the influence mechanism of error and resent culture on employees' dual performance, Economic Management, 5 (2017) 103-116.

5. B.Schneider, V.González-Romá, C.Ostroff, et al. Organizational climate and culture: reflections on the history of the constructs in the journal of applied psychology, Journal of Applied Psychology, 102(3) (2017) 468-482.

6. M.Frese and N.Keith, Action errors, error management, and learning in organizations, Annual Review of Psychology, 66 (2015) 661-687.

7. R.F.Yin, Research on the influence of leadership style on error management culture and organizational innovation performance, Leader Science, 9z (2012) 43-45.

8. X.N.Miao, Research on the relationship between leadership style, error orientation and employees' innovative behavior, Leader Science, 7z (2014) 46-48.

9. B.X.Zheng, L.F.Zhou, and J.L.Fan, Patriarchal leadership: construction and measurement of the ternary model, Indigenous Psychological Research, 14(2000)3-64.

10. A.Gold, U.Gronewold and S.E.Salterio, Error management in audit firms: error climate, type, and originator, Social Science Electronic Publishing, 89(1) (2014) 303-330. 
Research on the Influence of Leadership Style on Error Management Climate

11. A.C.Edmondson, Learning from errors is easier said than done: group and organizational influences on the detection and correction of human error, The Journal of Applied Behavioral Science, 32(1) (1996) 5-28. 